\title{
REFLETINDO SOBRE A EDUCAÇÃO INCLUSIVA: UMA TRAJETÓRIA ESSENCIAL PARA REPENSAR A EDUCAÇÃO FÍSICA ${ }^{1}$
}

\author{
REFLECTING ON INCLUSIVE EDUCATION: A TRAJECTORY \\ ESSENTIAL TO RETHINK PHYSICAL EDUCATION
}

\author{
Ana Aparecida Tavares da Silveira² \\ Fabyana Soares de Oliveira ${ }^{3}$ \\ Maria Aparecida Dias ${ }^{4}$
}

\begin{abstract}
Resumo
O presente artigo é um recorte de uma pesquisa de mestrado e tem como objetivo discutir as concepções de educação inclusiva dos professores de educação física da rede pública de uma cidade do Rio Grande do Norte e o impacto dessas para a educação física numa perspectiva inclusiva. Trata-se de uma pesquisa descritiva, com abordagem qualitativa e traz, como resultados, respostas atreladas, quase exclusivamente, à participação dos alunos com deficiência nas aulas. Com isto, percebe-se falta de clareza diante da educação física inclusiva, possivelmente ligada a conhecimentos restritos sobre a educação inclusiva, exigindo que os professores se aprofundem sobre essa temática, bem como assumam atitudes mais proativas.
\end{abstract}

Palavras-chave: Educação Inclusiva. Educação Física Inclusiva. Escola.

\begin{abstract}
This article is an excerpt from a master's research and aims to discuss the conceptions of inclusive education of physical education teachers in public schools in a city in Rio Grande do Norte and their impact on physical education in an inclusive perspective. It is a descriptive research, with a qualitative approach and brings, as a result, responses

\footnotetext{
${ }^{1}$ Recorte de uma pesquisa de mestrado concluída e intitulada "Educação física escolar inclusiva: olhares e saberes de um grupo de professores do ensino público do Natal/RN", realizada na linha de pesquisa Educação e Inclusão em Contextos Educacionais, pelo Programa de Pós-Graduação em Educação (PPGEd) da Universidade Federal do Rio Grande do Norte (UFRN). Parte do trabalho foi publicado nos seguintes eventos: 1o Congresso de Educação Física Escolar na Perspectiva Inclusiva; I Colóquio Internacional de Educação Especial e Inclusão Escolar; XXI Congresso Brasileiro de Ciências do Esporte e VIII Congresso Internacional de Ciências do Esporte.

${ }^{2}$ Doutoranda e Mestra em Educação pelo Programa de Pós-Graduação em Educação (PPGEd) da Universidade Federal do Rio Grande do Norte (UFRN), Graduada em Educação Física. E-mail: aatsacademico@gmail.com. (https://orcid.org/0000-0001-6232-1940)

${ }^{3}$ Doutoranda e Mestra em Educação pelo Programa de Pós-Graduação em Educação (PPGEd) da Universidade Federal do Rio Grande do Norte (UFRN), Graduada em Educação Física. E-mail: fabyanaoliv@yahoo.com.br. (https://orcid.org/0000-0001-6120-9105)

${ }^{4}$ Professora Doutora em Educação pela Universidade Federal do Rio Grande do Norte (UFRN). E-mail: cidaufrn@gmail.com. (https://orcid.org/0000-0003-3644-604X)
} 


\section{RevistAleph}

linked, almost exclusively, to the participation of students with disabilities in classes. With this, there is a lack of clarity in the face of inclusive physical education, possibly linked to restricted knowledge about inclusive education, demanding that teachers deepen on this theme, as well as assume more proactive attitudes.

Mais sobre o texto origina

Keywords: Inclusive Education. Inclusive Physical Education. School.

\section{Introdução}

Inclusão é um termo que se originou da palavra inglesa fullinclusion, dando início, na década de 1990, a um novo paradigma na educação, que se fundamentava a partir dos princípios dos Direitos Humanos. Percebia-se, que todo aluno que não participasse da vida social e educacional deveria frequentar a escola, lançando as primeiras sementes do descontentamento com a discriminação e a exclusão social (MANTOAN, 1997).

O paradigma da inclusão se intensificou na mesma década nos Estados Unidos, quando "uma organização internacional crescente (Schools Are For Everyone - As Escolas São Para Todos)" passou a reivindicar nos tribunais, a partir de vários casos diferentes, reformas na educação, com o propósito de promover a inclusão principalmente das pessoas com deficiência. No mesmo, ano a educação norte americana passa por uma reforma geral, excluindo os currículos escolares que se baseavam nas necessidades ou nos níveis de habilidade do aluno, na segregação e nas rotulações dos alunos com problemas de aprendizagens e aderiu, entre outras coisas, ao uso flexível de recursos que promovessem o sucesso na aprendizagem e a métodos que adaptassem o currículo e a instrução. O ensino inclusivo deveria garantir a participação de todos na escola, satisfazendo suas necessidades de aprendizagens, independente de seu talento, deficiência e origens cultural e econômica (KARAGIANNIS; STAINBACK; STAINBACK, 1999, p. 42).

Para Mantoan (2004, p. 15), a inclusão surge na tentativa de tornar possível que todos os alunos, sem exceção, possam frequentar as salas de aulas do ensino regular, superando a integração onde nem todos os alunos com deficiência cabiam nas turmas de ensino regular, visto que havia uma seleção prévia dos mais aptos à inserção, 


\section{RevistAleph}

sendo selecionados apenas os que eram considerados capazes de se adaptarem às exigências da escola, o que não gerava de fato um direito igualitário à educação.

A autora ainda acrescenta que a "inclusão é uma provocação, cuja intenção é melhorar a qualidade do ensino das escolas, atingindo todos os alunos que fracassam em suas salas de aula" (MANTOAN, 2004, p.15). No entanto, concretizar essas novas diretrizes para escola não é tão simples quanto possa parecer.

Reforçando a compreensão sobre o paradigma da inclusão, Martins (2006) mostra a importância de reconhecer que não basta inserir fisicamente o aluno na instituição, urge a necessidade de considerar outros elementos imprescindíveis e complexos, como:

1 Que o governo adote, efetivamente, políticas inclusivas e não apenas divulgue, através dos diversos meios de comunicação, que está promovendo a inclusão escolar e que, em decorrência disto, as escolas estão receptivas para receber a todos os educandos, sem exceção.

2 Buscar formas a fim de contribuir para mudar a escola, para tornála receptiva às necessidades de todos os alunos.

3 Ajudar os professores a refletir e a aceitar a sua responsabilidade quanto à aprendizagem de todos os educandos, colaborando assim para prepará-lo para ensinar àqueles que são comumente excluídos das escolas, por qualquer razão.

4 Proporcionar o envolvimento dos vários elementos que constituem a escola - do porteiro ao diretor - no processo inclusivo.

5 Possibilitar que os educandos com necessidades especiais ${ }^{5}$, efetivamente, possam se sentir parte integrante daquele ambiente educacional, aceitos e apoiados por seus pares e pelos demais membros da escola (MARTINS, 2006, p. 19).

Ao elencar os elementos acima, a autora mostra que a educação inclusiva está envolta por vários atores e muitas nuances, exigindo da sociedade um maior envolvimento, e da comunidade escolar maior aprofundamento dos fundamentos que compõem o paradigma da inclusão, a fim de implementá-la de fato. Para os educadores,

\footnotetext{
${ }^{5}$ Termo em desuso, atualmente a nomenclatura correta é "pessoa com deficiência".
} 


\section{RevistAleph}

emerge a necessidade de se qualificar melhor para conviver diariamente com os alunos com deficiência nos ambientes escolares.

De acordo com Martins (2015), no Brasil, até meados da década de 1980, não havia preocupação por parte das universidades em formar profissionais qualificados que pudessem garantir a inclusão ou acesso das pessoas com deficiência aos serviços oferecidos na sociedade, isto porque as discussões sobre educação inclusiva ainda estavam sendo germinadas, sobretudo, nos países do ocidente.

Na graduação em educação física, preocupações como estas começaram a se consolidar um pouco antes com a aprovação do Parecer $n^{\circ} 215$ pelo Conselho Federal de Educação em 11 de março de 1987, que criou, entre outras, a disciplina Educação Física Adaptada para compor o currículo dos cursos de graduação em Educação Física por todo Brasil. A disciplina era voltada para o atendimento das pessoas com Necessidades Educacionais Especiais (NEEs) (CHICON, 2010).

Em 1994, o Ministério da Educação brasileiro recomendou que os cursos de formação de docentes, assim como outras áreas do conhecimento, em que os profissionais interagem com pessoas com deficiência, deviam complementar seus currículos da seguinte maneira: para os cursos de Pedagogia, Psicologia e todas as licenciaturas indicou prioritariamente a disciplina "Aspectos Éticos - Políticos Educacionais da Normalização e Integração da Pessoa Portadora de Necessidades Especiais ${ }^{\prime \prime} ;$ para os cursos de Educação Física, Enfermagem, Fisioterapia, Fonoaudiologia, Medicina, Nutrição, Odontologia, Terapia Ocupacional, os conteúdos referentes "Aspectos Éticos - Políticos - Educacionais da Normalização e Integração da Pessoa Portadora de Necessidades Especiais" ${ }^{7 \prime \prime}$, e para os demais cursos de nível superior, recomendou a manutenção e ampliação dos estudos nesta mesma perspectiva, além disso, incentivou a abertura de novos cursos acadêmicos que tratassem da Educação Especial (MARTINS, 2015).

A Educação Especial ganhou destaque na educação física com o esporte adaptado, mas, embora a educação física adaptada tenha dado os primeiros passos

\footnotetext{
${ }^{6}$ Termo obsoleto, atualmente a nomenclatura correta é "pessoa com deficiência".

7 Idem.
} 


\section{RevistAleph}

rumo às discussões sobre inclusão nesta área, não se configura como educação física inclusiva. De acordo com Leopoldino (2018), a educação física adaptada se difere da educação física inclusiva por propor atividades que são desenvolvidas exclusivamente por pessoas com deficiência. Desse modo, apesar de oportunizar aprendizagem para as pessoas com deficiência, não se configura como educação física inclusiva, tendo em vista que:

De acordo com o princípio da Inclusão, a Educação Física escolar deve ter como eixo fundamental o aluno e deve se voltar para o desenvolvimento das competências de todos os alunos e proporcionar condições de acesso aos conteúdos a partir de estratégias adequadas (FERREIRA; DAOLIO, 2014, p. 63).

A educação física na perspectiva inclusiva apresenta como possibilidade a ampliação do repertório de vivências por meio da apropriação do conteúdo, a partir de estratégias que viabilizem o desenvolvimento e aprendizagem de todos os alunos, sejam eles com ou sem deficiência.

Destarte, os conceitos de educação física adaptada e educação física inclusiva apresentam divergências em seus propósitos, mas não é incomum encontrar professores de educação física que os percebam de forma semelhante, trabalhando a educação física adaptada nas escolas como se estivessem realizando inclusão. A falta de clareza diante das próprias especificidades da educação física, numa perspectiva inclusiva, nos faz refletir se isto ocorre em virtude da ausência de aprofundamento sobre a educação inclusiva.

Neste sentido, trazemos duas questões para nortear as discussões deste trabalho: os professores de educação física percebem os elementos que compõem a educação inclusiva? O conhecimento oriundo da educação inclusiva contribui para compreender as especificidades da educação física inclusiva? Para fomentar as discussões dessas questões, reportamo-nos a um recorte de uma pesquisa de mestrado aprovada pelo comitê de ética ${ }^{8}$ que teve como objetivo analisar as percepções de inclusão de trinta e nove professores de educação física que frequentaram, em 2018, a

\footnotetext{
${ }^{8}$ Certificado de Apresentação para Apreciação Ética (CAAE): 09697119.5.0000.5292.
} 


\section{RevistAleph}

formação continuada oferecida pela Secretaria Municipal de Educação do Natal (SME/Natal) no Rio Grande do Norte.

\section{Metodologia}

Antes de adentrar mais especificamente nos aspectos metodológicos, percebese a necessidade de trazer algumas informações sobre o público-alvo e o campo empírico. O perfil dos professores pesquisados é constotuído por vinte pessoas do sexo feminino e dezenove do sexo masculino, tendo em sua maioria a idade acima de trinta anos. Seis professores informaram que, além da formação em educação física, também possuem outra formação (Filosofia, Engenharia Civil, Biologia, loga-Massoterapia, Pedagogia e Técnico em Turismo), e trinta e seis professores concluíram o curso de Educação Física em instituições públicas no Nordeste brasileiro.

O campo empírico foi as formações continuadas dos professores de educação física oferecidas pela SME/Natal, que ocorrem de quinze em quinze dias, nas segundasfeiras, com 4h de duração para cada grupo, de acordo com o turno escolhido (matutino ou vespertino), sendo opcional a participação do professor tanto nos encontros quanto no turno que puder comparecer. Desse modo, se o professor optar por não frequentar, deverá obrigatoriamente se fazer presente na escola que leciona para cumprir o horário destinado ao planejamento semanal (NATAL, 2017).

$\mathrm{Na}$ referida pesquisa de mestrado, foi utilizado o método descritivo e o instrumento de coleta de dados, um questionário estruturado com questões objetivas e subjetivas, aplicado no primeiro encontro da formação continuada de 2019. No momento da aplicação, foi solicitado aos professores que escolhessem um nome fictício a ser utilizado nas análises das questões e nas demais produções textuais e, para aqueles que não quiseram criar um pseudônimo, designamos nomes fictícios.

As análises dos dados coletados foram realizadas por meio da abordagem qualitativa, gerando interpretações que estabeleceram ligação entre os resultados da pesquisa e outros conhecimentos preexistentes. Durante as análises, foram detectados temas e temáticas mais e menos frequentes, tais como "questões de gênero", "etnico- 


\section{RevistAleph}

racial", "pessoa com deficiência", "educação para todos", "acesso à cultura de movimento" e "capacitação", entre outras que deram origem assim a três categorias de estudo: educação inclusiva; educação física inclusiva; e formação continuada e inclusão.

Neste recorte, será explorada a categoria educação inclusiva, tendo como objetivo discutir a educação física inclusiva a partir dos elementos que foram identificados pelos professores como componentes da educação inclusiva. Entre estes destacam-se: educação para todos, expressando a notoriedade diante da inclusão da pessoa com deficiência, bem como dos sujeitos excluídos a partir das questões de gênero e étnico-racias; as barreiras à inclusão, discutindo o envolvimento da comunidade escolar, da sociedade e do governo, a inserção da inclusão no Projeto Político Pedagógico (PPP) da escola e a fragilidade dos conhecimentos dos professores sobre as tipologias das deficiências; e por fim, O saber fazer ligado à subjetividade do aluno.

\section{Resultados e discussões: Discutindo percepções e refletindo sobre algumas de suas nuances}

\section{Educação Para Todos}

A categoria educação inclusiva teve como base a questão: “O que é para você uma Educação Inclusiva?" Foi possível observar que dos trinta e nove professores entrevistados trinta demonstraram entender a educação inclusiva como uma concepção de ensino que privilegia todos os alunos. A partir desses dados, percebeu-se que a maioria dos sujeitos da pesquisa ressalta a diversidade presente na escola, como é possível verificar em algumas das respostas:

Não é só incluir pessoas com deficiência, mas também fazer com que pessoas gordas, meninas, meninos, enfim todas as crianças e jovens participem das aulas (em geral) do processo formativo escolar, inclusive na Educação Física (Ely).

A prática educativa que proporciona a vivência, em todos os seus níveis (teórico/prático), por todos os alunos, independente de suas limitações físicas, mentais, intelectuais ou sociais (Chico). 


\section{RevistAleph}

Educação onde todos tenham oportunidades, com igualdade, com valorização das diferenças sociais, culturais, gênero, físicas, intelectuais, garantindo o acesso de todos (Leon).

As respostas acima descritas nos revelam que a compreensão dos professores sobre educação inclusiva está em consonância com as definições defendidas por autores como Martins (2006), Cidade e Freitas (2002), Glat e Blanco (2009), Mantoan (1997; 2004) quando defendem que os alunos devem, independentemente de qualquer condição, ser acolhidos e respeitados em suas diferenças no âmbito da escola regular. Desse modo, percebe-se que a maioria dos professores entende a educação inclusiva de forma ampliada a todos os alunos e não apenas pelo viés da pessoa com deficiência.

Ao comparar os dados obtidos acima com as respostas da questão "O que é para você uma Educação Física Inclusiva?", percebeu-se que um número muito aproximado de professores (trinta e dois) também compreende a educação física inclusiva sob o mesmo ponto de vista, voltada para todos, mostrando, em alguns casos, que é preciso um olhar diferenciado para diversidade, como se observa abaixo:

É a Educação Física que se preocupa em realizar atividades que sejam praticadas por todos os alunos com ou sem necessidades especiais (Pepa).

Fazer com que todos os alunos participem das aulas, independente de habilidades, aspectos físicos, intelectuais, sociais, gênero, onde todos participem sem exceção (Leon).

Assim, essas respostas atribuem à educação física inclusiva o mesmo sentido fornecido à educação inclusiva, uma vez que não apresentam as especificidades, que trataremos mais à frente, revelando fragilidades diante do papel da educação física e da inclusão de seus alunos na escola, o que pode estar deixando os professores ainda muito confusos.

Como exemplo dessas especificidades, Boato (2010, p. 116) mostra que "ainda não conseguimos incluir aqueles alunos que não se encaixam nos modelos preestabelecidos como os "gordinhos", os "baixinhos", os "magricelos", os "inábeis", os "desajeitados", entre outros". Isso porque a Educação Física esteve durante muito tempo preocupada demasiadamente em desenvolver habilidades esportivas, visando o 


\section{RevistAleph}

desempenho em competições. Tais dificuldades somam-se à inclusão do aluno com deficiência que apresenta outras limitações e que não se encaixam em atividades padronizadas, bem como as meninas que culturalmente foram e ainda são enquadradas em papéis sociais que as excluem de atividades que não são consideradas culturalmente para seu gênero.

A discussão de gênero relacionada à inclusão também foi encontrada em uma das respostas do questionário, na questão que solicitava o relato de uma experiência inclusiva significativa:

Muitas vezes em jogos com caráter competitivos a escolha das equipes se resumia a um único gênero. Por ser recorrente foi imposta a regra de times mistos o que possibilitou a quebra dos estereótipos estabelecidos pelos alunos (Denilshow).

Ao tratar de uma experiência ligada à discussão de gênero nas aulas de educação física, o professor Denilshow nos faz refletir sobre a escola como parte integrante da sociedade que reproduz exclusão não somente a partir das relações que se estabelecem com as pessoas com deficiência. Abrange também outros sujeitos, como é o caso das meninas junto aos meninos nas aulas de educação física, que aparentemente estão em situação de igualdade, mas que na prática não estão, decorrente da falta de oportunidade de participação.

Caso o professor tivesse permitido a separação das equipes por sexo/gênero, estaria contribuindo para reforçar a segregação sexual que durante muito tempo esteve presente, e ainda está, nas aulas de educação física no Brasil, e que só veio a se modificar a partir da década 1990, conforme Jesus e Devide (2006), com discussões sobre a Coeducação. Para os referidos autores, tal resistência em compor equipes mistas só ocorre até o momento em que os meninos percebem que há meninas habilidosas.

Por este fator, no início do ano letivo, quando alunos e alunas são estimulados a participarem de aulas Mistas, identificamos o sentimento de recusa por parte de ambos os grupos. A problematização da construção cultural das diferenças de gênero em relação à participação de homens e mulheres em determinadas modalidades de desporto, a partir de discussões construídas na 


\section{RevistAleph}

interação das aulas, tende a diminuir os conflitos de gênero entre os sexos. A intervenção pedagógica do docente torna-se fundamental para a desconstrução de alguns estereótipos e a minimização da separação dos sexos nas aulas de EFe, incentivando a prática de alunos e alunas nas mesmas atividades corporais, contribuindo para o desenvolvimento da solidariedade, gerando um melhor entendimento da construção social das diferenças de gênero e consequentemente, a tolerância de ambos os sexos, sobre o seu desempenho nas atividades motoras propostas (JESUS; DEVIDE, 2006, p. 129).

Destarte, ao permitir atividades separadas, o professor estaria contribuindo para reforçar as diferenças entre os sexos/gêneros, o que geraria mais exclusão das meninas. Além dessas questões de gênero, também foram mencionadas questões étnico-raciais nas descrições de experiências inclusivas:

Etnia racial, uma dinâmica na quadra, "jogo das diferenças", em conjunto com outras matérias da escola e palestrantes que dominam o conteúdo desse tema. Muito significativo para todos nós (Patrícia Conceição).

Embora a experiência relatada pela professora não esteja detalhada, pois enriqueceria a análise, entende-se que oportunizar experiências para discutir as diferenças são essenciais no âmbito escolar, pois traz à tona a compreensão de uma realidade muito presente na construção histórica da sociedade brasileira, a exclusão étnico-racial, principalmente da população negra.

Em relação a isso, Silva (2009, p. 197) destaca que "pensar o acesso da população negra aos direitos sociais, econômicos, culturais e jurídicos no Brasil é considerar o processo histórico que marca e define 'o lugar' dos negros e negras na sociedade brasileira [...]", lugar este que perpassa por uma trajetória de exclusão e de resistência.

De acordo com Souza (2015), as políticas de ampliação de vagas escolares para a Educação Básica são maiores para os "não brancos" do que para os brancos, entretanto, quando se observa quem tem mais anos de estudo, o número se inverte, ficando os brancos à frente no que refere à escolaridade. Esses dados ganham maior proporção quando somados ao ensino superior, indicando a predominância de um 


\section{RevistAleph}

grupo privilegiado no acesso ao ensino superior, em que os negros não estão em condições de igualdade com os considerados brancos.

Diante da precariedade de vida em que se encontra a população pobre no Brasil, a população negra é, de forma evidente, um dos segmentos mais vulneráveis ante o processo de aviltamento da vida humana resultante das relações sociais capitalistas, pois, no capitalismo, as desigualdades sociais, econômicas, políticas e culturais são permeadas pela discriminação e pelo preconceito racial, favorecendo a recriação constante das diferenças, segundo as leis da divisão do trabalho social e da estratificação social, o que se contradiz a "idéia" de cidadania e de trabalhador livre, ao mesmo tempo em que as diferenças de classe e raça são mantidas e recriadas no processo de organização coletiva da sociedade (SILVA, 2009, p. 201).

Desse modo, entende-se que as questões étnico-raciais no Brasil, principalmente dos negros, precisam estar presentes nas pautas pedagógicas da escola como aspecto relevante ao paradigma da inclusão, bem como as questões de gênero, tendo em vista as múltiplas exclusões às quais são submetidas as mulheres, entre outros sujeitos.

As temáticas de gênero e étnico-raciais também foram exploradas como alternativas em uma questão objetiva do questionário: “A educação física inclusiva pode ser trabalhada, considerando quais questões?" Como alternativa tínhamos: a) Questões de gênero e deficiências; b) Questões de deficiências; c) Questões de gênero, deficiências e étnico-raciais; d) Nenhuma das questões acima. Uma parte composta por vinte e nove professores marcaram a alternativa " $c$ ", revelando em outro espaço do questionário que percebem a educação inclusiva de maneira mais ampla, englobando aspectos que extrapolam as pessoas com deficiência.

Todavia, a pesquisa apontou ainda que apenas dois dos trinta professores que entendem a educação física inclusiva voltada para todos os alunos relataram alguma experiência significativa relacionada às questões de gênero e étnico-raciais, embora estas questões ligadas à educação inclusiva sejam tão ou mais presentes no cotidiano escolar que as exclusões das pessoas com deficiências. Esses dados nos revelam como tais questões ainda são carentes de aprofundamento, principalmente no que diz respeito a sua ligação com a educação inclusiva. Assim, entende-se que compreender 


\section{RevistAleph}

as questões de gênero e étnico-raciais como elementos fundamentais da educação inclusiva pode ajudar a educação física a trilhar caminhos que se aproxime mais de aulas inclusivas e contribuir na formação de cidadãos que combatam situações de exclusão vividas no contexto social, para além da sala de aula.

A exemplo disto, a educação física pode discutir, por meio dos seus próprios conteúdos, questões étnico-raciais e de gênero, que são muito fáceis de encontrar no contexto do esporte profissional, principalmente no futebol, em que jogadores são tratados de forma hostilizada pelos torcedores em virtude da cor de sua pele. Destacase alguns $\operatorname{casos}^{9}$ : Aranha, goleiro dos Santos, que em 2014 levou dois gols em um jogo contra o Grêmio e, por isso, foi chamado de macaco; Tilica, atacante do Caxias, que em 2020 ao passar próximo da torcida durante sua substituição no jogo foi cuspido, chamado de favelado e de macaco; e Neymar, atacante do Paris Saint-Germain, foi também chamado de macaco no jogo contra Olympique de Marselha no campeonato Francês de 2020.

É possível também discutir como a exclusão das meninas na prática do futebol, na escola, na rua, nas escolinhas de futebol, entre outros espaços, desvaloriza o futebol profissional feminino. Por que as mulheres são vistas como menos habilidosas no futebol? Por que não conseguem a mesma notoriedade dos jogadores? Até mesmo a jogadora Marta, que já foi eleita seis vezes a melhor jogadora de futebol do mundo, recebe menos atenção e um salário bem inferior ao de Neymar, que foi indicado oito vezes ao prêmio e nunca ganhou o título.

Esses exemplos trazem à tona as desigualdades de oportunidades postas aos sexos/gêneros que, muitas vezes, começam nas aulas de educação física, quando os meninos não deixam as meninas participarem do futebol, e os professores não tomam nenhuma atitude que reverta a situação. O futebol está tão vinculado aos homens na sociedade brasileira que, em muitos casos, nem se percebe que o fato de não

\footnotetext{
9 Segue alguns sites onde é possível ler um pouco mais sobres estes casos: http://www.espn.com.br/noticia/436034_aranha-e-chamado-de-macaco-por-torcida-do-gremio; https://www.uol.com.br/esporte/futebol/ultimas-noticias/2020/03/10/fui-chamado-de-macaco-efavelado-diz-atacante-tilica-apos-jogo-no-gaucho. $h t m$ ?cmpid=copiaecola; https://jovempan.com.br/esportes/futebol/futebol-internacional/neymar-foi-chamado-de-macacoconfirmam-especialistas.html.
} 


\section{RevistAleph}

oportunizar o acesso ao futebol às meninas nas aulas de educação física, bem como aos outros alunos menos habilidosos, é uma atitude excludente por parte do professor. Entende-se, assim, que estas questões merecem mais atenção ao se pensar em uma educação para todos.

\section{Barreiras à inclusão}

Embora a inclusão seja discutida em vários espaços que compõem a sociedade, tais como na educação, na saúde, no trabalho, no lazer, na habitação, no esporte, ainda não conseguiu ser priorizada pela sociedade como um todo. Na escola essa realidade não é diferente, como apontou a pesquisa que aqui está sendo parcialmente discutida.

Quando questionados "Quais aspectos você considera como facilitadores para inclusão na escola em que trabalha?" e "Quais aspectos você considera como barreiras para inclusão na escola em que trabalha?", os professores responderam as duas questões com basicamente os mesmos itens: aspectos ligados a políticas públicas, às atitudes, à infraestrutura, ao conhecimento sobre as deficiências, aos professores auxiliares e às ações pedagógicas. Só houve dois enfoques diferentes em relação ao Atendimento Educacional Especializado ( $A E E)$ que apareceu apenas como facilitador, por realizar um trabalho pedagógico paralelo ao da sala de aula, facilitando a aprendizagem do aluno com deficiência; e a família apareceu somente como barreira, uma vez que, na maioria dos casos, não colabora de forma satisfatória com a escola a fim de favorecer a inclusão do seu filho.

Todavia, embora os professores tragam tantos pontos a serem explorados no entendimento sobre a educação inclusiva, não conseguem expandir a compreensão de suas aulas, enfocando nos demais sujeitos envolvidos no processo de inclusão na escola, limitando-se a responder que suas aulas são parcialmente inclusivas porque não conseguem envolver todos os alunos, ou seja, expressam um entendimento sobre aulas inclusivas a partir da garantia da participação dos alunos com deficiência nas aulas de educação física, como será possível observar na discussão abaixo.

A pesquisa revela que dez pessoas do público pesquisado consideram suas aulas inclusivas, e vinte e nove consideram parcialmente. Ao justificar o porquê de 


\section{RevistAleph}

considerar as aulas parcialmente inclusivas, os professores, em sua maioria, disseram que não conseguem envolver todos os alunos, apesar de se esforçarem para contemplálos. Nessas respostas fica perceptível que a maior dificuldade do professor é envolver o aluno com deficiência, contudo, ao responder à questão que solicitava relatos de experiências inclusivas, trinta e cinco professores descreveram relatos com alunos com deficiência ou com transtornos, como se observa em alguns dos exemplos abaixo.

Um aluno autista, embora tenha sido promovido, preferia vir fazer aulas práticas com minhas turmas ao invés de seu novo professor (Stillo).

O autista da minha escola participa de quase todas as minhas aulas de Educação Física. Para ele é a aula que motiva ele a estar na escola e aprender em sala de aula (Elis).

Tanto no primeiro relato, quanto no segundo, os professores defendem que suas aulas são inclusivas tomando por base a participação dos alunos "autistas" nas aulas de educação física. Ao que parece nos relatos acima citados, nenhum dos professores de educação física cita o Transtorno do Espectro Autista (TEA), mas fala "o autista", será que há uma ampla compreensão acerca do espectro? Acredita-se que não. Um pouco mais na frente será possível perceber que os professores anseiam por capacitações que possam aprofundar os conhecimentos sobre as tipologias das deficiências, e o TEA é uma das temáticas solicitadas.

Fatos como esses mostram a motivação dos professores em tentar realizar práticas mais inclusivas, o que não quer dizer que a perspectiva inclusiva presente nesses relatos não seja questionável. Primeiro por estar reduzindo o conceito de educação física inclusiva apenas à participação do aluno com TEA em suas aulas; segundo porque os motivos pelos quais os alunos participam estão envoltos por outros aspectos que compõem o contexto escolar (MARTINS, 2006) e que necessariamente deveriam ser considerados, como o envolvimento da comunidade escolar, as políticas públicas e as possíveis ausências das barreiras físicas, atitudinais e procedimentais.

Sobre alguns desses aspectos, Pires (2006, p. 84) enfatiza a importância do envolvimento da comunidade escolar no processo de inclusão na escola, defendendo que é preciso transformar a instituição "numa comunidade educativa de partilha de 


\section{RevistAleph}

trabalho e de cultura, com o envolvimento de todos [...]. Nunca será demais estimular, de todas as formas, a participação de todos os que fazem a escola, incluindo, aí, a família e a comunidade". Acrescenta-se a tais membros os funcionários de diversos setores, os professores, a coordenação e a direção da escola.

Além disso, é importante destacar que "esse processo de reconhecimento de uma educação inclusiva precisa ainda de um apoio interinstitucional e da sociedade, para monitorar a inclusão dos diferentes grupos de estudantes com deficiência, no âmbito privado ou público" (VÍLCHEZ, 2018, p. 13), entendendo que muitas ações inclusivas não se concretizam por falta de cobranças ao estado e ao município.

Como outra barreira, aparece a falta de conhecimento aprofundado dos professores sobre a educação inclusiva. Ficou perceptível nas questões "O que é para você uma Educação Inclusiva?" e "O que é para você uma Educação Física Inclusiva?". Três professores descreveram a educação inclusiva voltada apenas para pessoas com deficiências, e duas também revelaram essa mesma compreensão no que diz respeito à educação física inclusiva:

Aquela que assegura aos portadores de necessidades especiais o direito à educação, com a participação do acompanhamento específico para cada criança (Nascimento).

Ampliação das oportunidades educativas aos alunos portadores de deficiências intelectuais e motoras (Gue).

Que para toda atividade tem sempre algo que a criança com deficiência possa participar (Come Sopa).

Capacidade do professor de Educação Física incluir alunos especiais nas aulas com adaptação das temáticas (Avatar).

Os usos obsoletos dos termos "portadores de necessidades especiais", "portadores de deficiência" e "alunos especiais" denunciam, à primeira vista, a desatualização dos professores diante das discussões sobre inclusão. Embora não tenha havido uma profunda mudança social nas atitudes dos sujeitos diante do engajamento em prol da inclusão e do respeito a todos como cidadãos de direitos, as substituições das terminologias para "pessoa com deficiência", segundo Ferreira (2013), modificaram a interpretação que temos sobre elas. Desta maneira, para ser chamado de portador, o 


\section{RevistAleph}

sujeito precisa está carregando algo que em outro momento não estará portando mais, o que não é possível quando se refere à deficiência. Ao ser chamado de aluno especial restringe essa especificidade apenas para um ou alguns, desprezando os demais, que para a educação inclusiva são também especiais.

Essa forma de compreender a educação inclusiva pelo viés apenas da pessoa com deficiência está atrelada aos objetivos da Educação Especial. Acredita-se mais uma vez que é compreensível, em decorrência do movimento frente à inclusão que teve e ainda tem nas conquistas da educação inclusiva, mas pensar o processo de inclusão apenas com esse viés voltado à deficiência é limitá-lo. Para Soler (2005), a inclusão precisa envolver todas as diferenças, pois as oportunidades devem ser iguais para todos.

Essa discussão é tratada por Carvalho (2000, p. 160) como dualismo de concepções que separam a Educação Regular da Educação Especial, “[...] tratando de duas educações diferentes, com finalidades diferentes, talvez porque, no imaginário coletivo, os sujeitos de cada uma estejam com cidadanias diferentes também [...]". Para a autora, esse equívoco ao entender a Educação Especial como subsistema à parte tem provocado grandes entraves na escola, um deles é que toda orientação ou cursos que tratam da Educação Especial são direcionados para os profissionais do Atendimento Educacional Especializado (AEE), limitando à informação e segregando ainda mais os demais educadores do processo de elaboração, discussão e implementação de atividades inclusivas na escola.

Outro entrave trata-se de compreender erroneamente que a competência teórico-metodológica da(o) profissional do AEE “enquanto educador pode ser 'menor', pois se destina a um alunado igualmente 'menor', percebido como incompetente, excluindo-o da escola e da ordem social" (CARVALHO, 2000, p. 163). Deste modo, os professores do AEE ficam quase sempre isolados dentro do contexto escolar, realizando em muitos casos atendimentos sem a participação dos demais professores da escola, dificultando, assim, um trabalho mais colaborativo e mais informativo para toda a comunidade escolar.

Diante dessa situação, fica visível a urgência de intensificar as discussões sobre a inclusão dentro da escola, de modo que possam ser repensadas essas dicotomias que 


\section{RevistAleph}

interferem na relação que se estabelece entre a Educação Regular e Especial, bem como que possam contribuir para eliminar as barreiras em prol da educação inclusiva.

Essas dicotomias talvez façam parte também das percepções dos professores pesquisados, podendo ser consequência da falta de prioridade no trato da educação inclusiva por parte das escolas em todo Brasil. Sobre isto, a pesquisa identifica que em apenas duas das escolas, onde os professores lecionam, existem discussões sobre inclusão, sendo realizadas em três espaços de construção pedagógica: nas reuniões de planejamento coletivo e individual com o coordenador e na construção do Projeto Político Pedagógico (PPP). Na maioria das escolas (trinta e três), essas discussões ocorrem em dois dos ambientes pedagógicos citados, variando as combinações entre eles. Além disso, apareceu na pesquisa uma escola que discute inclusão na semana pedagógica e outra no planejamento com a professora do AEE.

Ou seja, os dados acima sugerem que o debate sobre a educação inclusiva ainda não é uma realidade consolidada em boa parte das escolas dos sujeitos que participaram da pesquisa, o que com certeza vem interferindo no modo de conceber a educação inclusiva e, por consequência, influenciando na percepção do papel da educação física dentro deste contexto.

Observou-se ainda, em função dos dados obtidos, que essa ausência de conhecimentos mais aprofundados sobre os diversos aspectos que compõem a educação inclusiva vem deixando os professores inquietos. Na pesquisa, identificou-se que esses sujeitos desejam participar de cursos e capacitações que possam trazer conhecimentos que Ihes possibilitem lidar com dificuldades encontradas. Todavia, em virtude das demandas mais urgentes da prática pedagógica, que exige novas atitudes diante dos alunos com deficiência, não conseguem perceber a importância de conhecer os elementos que subsidiam o paradigma da inclusão como alicerce fundamental para pensar a educação física inclusiva.

Para um dos professores, qualquer conhecimento novo sobre inclusão é importante para sua formação como educador; e duas expressaram que desejam conhecer mais sobre a história, conceitos e princípios que compõem a educação inclusiva. Ou seja, acredita-se que apenas três dos sujeitos da pesquisa percebem a 


\section{RevistAleph}

importância de compreender o processo de inclusão numa perspectiva mais complexa, que não envolve somente os aspectos metodológicos aplicados nas suas aulas, mas todo um contexto social, político, cultural e econômico que determina o modo de entender a sociedade.

Contudo, quatro pessoas do grupo pesquisado mostraram o desejo de aprender sobre atividades práticas que pudessem envolver todos os alunos, incluindo os mais resistentes à participação, os que estão acima do peso e as meninas; e trinta professores desejam práticas inclusivas que atendam às necessidades dos alunos com deficiência, enfocando atividades para alunos com múltiplas deficiências, com Transtorno do Espectro Autista, com Deficiência Mental, Paralisia Cerebral, Microcefalia e com Síndrome de Down.

Isto nos revela a preocupação desse público com o saber fazer diante das especificidades de cada deficiência a fim de compreender melhor suas limitações e possibilidades para planejar atividades apropriadas.

\section{O saber fazer}

Ao discutir o saber fazer do professor de Educação Física ligado à inclusão, Dias e Lopes (2012, p. 46) mostram que

\footnotetext{
É importante conhecer tais características para melhor aplicação das nossas propostas pedagógicas. Sob o ponto de vista motor, as crianças com Síndrome de Down irão apresentar dificuldades na aquisição da motricidade motora global, equilíbrio, organização espacial e organização motora fina, visto que é característica da Síndrome de Down a hipotonia.
}

Para as autoras, os professores sentem necessidade de conhecer as especificidades cognitivas, emocionais e fisiológicas das deficiências de seus alunos a fim de compreender melhor suas limitações e possibilidades. Para subsidiar essa demanda, Dias e Lopes (2012) apontam alguns elementos que explicam as tipologias das deficiências, perpassando por categorias definidas por deficiências física, mental ou intelectual e sensorial e por graduações de intensidade que podem ser leve, moderada, severa ou profunda. Mas, ao mesmo tempo em que demonstram compreender as 


\section{RevistAleph}

características específicas das deficiências como fundamental para pensar em atividades apropriadas que estimulem o desenvolvimento dos alunos, também advertem que os professores não podem ficar atrelados apenas a essas características para compreendê-los.

Todavia, na escola, o diagnóstico médico é quem diz se um aluno precisa de um atendimento diferenciado ou não, o que dificulta pensar as deficiências para além das suas características clínicas, gerando, muitas vezes, preconceitos, que estigmatizam as possibilidades de participação e aprendizagem dos alunos. O que contribui para que o professor supervalorize o saber fazer associado ao conhecimento clínico das pessoas com deficiência como essencial para sua qualificação profissional. Conforme Carvalho (2000, p. 167), o saber fazer

Diz respeito ao transmitir e ao formar. Sob o primeiro aspecto consideram-se todas as habilidades necessárias ao ensino, de modo que o momento pedagógico seja agradável e produtivo ao sucesso na aprendizagem. Em relação à formação do aluno, o saber fazer está relacionado a aspectos éticos que compõem a formação pessoalprofissional de cada educador. Refiro-me, em particular: aos valores que o professor cultua e transmite (a partir de suas próprias atitudes frente às diferenças individuais); à sua prática e ao modelo de sociedade que idealiza.

Percebe-se, assim, que o saber fazer é muito mais complexo que a mera aprendizagem de métodos e técnicas que auxiliem o professor com os alunos com deficiência. Todavia, a interpretação feita dos dados em discussão foi um entendimento contrário, visto que os professores o compreendem exclusivamente a partir da aquisição de modelos pré-estabelecidos que sirvam de manual, respaldados em métodos e técnicas.

Para Glat e Blanco (2009, p. 187), esse tipo de entendimento sobre o saber fazer vinculado ao domínio de métodos e técnicas específicas para as pessoas com deficiência emergiu com os educadores da Educação Especial. A partir disso, passou a fazer parte da compreensão de todos os professores, incluindo o de educação física, pois é consensual que "[...] precisam acumular um saber sobre as características das diferentes manifestações da deficiência para melhor dominarem a tecnologia do ensino 'adequada' a cada tipo de deficiência. Defendem, ainda, que essa é uma forma 


\section{RevistAleph}

equivocada de conhecer os modos e os meios de ensinar a qualquer pessoa com deficiência, tendo em vista que, ao se utilizar apenas de métodos específicos, o professor se apropria apenas de uma formação tecnicista, como se esta fosse o fio condutor de sua formação.

Para as autoras, os professores deveriam se especializar no aluno, compreendendo que ele constrói conhecimento, tem sentimentos, desejos e saberes adquiridos em sua vida extraescolar, trazendo esse conhecimento pré-existente para escola. Embora apontem essa crítica, Glat e Blanco (2009) não descartam a importância dos conhecimentos teóricos-metodológicos, nem tão pouco das tipologias, mas destacam que o mais importante nesse processo é a diversidade das ofertas educativas disponibilizadas a todos, considerando que todos os alunos merecem atenção e respeito, devendo receber o reconhecimento por suas subjetividades.

Deste modo, entende-se que discussões como essas realizadas na educação inclusiva permitem outros olhares para o saber fazer, bem como servem para refletir sobre o papel da educação física enquanto área do conhecimento, que precisa ser garantida aos alunos. Ainda sobre o saber fazer, Chicon e Sá $(2012$, p. 103) mostram que

[...] a Educação Física deve se apoiar em profissionais que não possuem apenas a habilidade de executar uma ação pedagógica, mas autonomia para analisar, criar, recriar caminhos para se potencializar tais habilidades, com o objetivo de levá-las ao pleno desenvolvimento das potencialidades de seus educandos considerando os diferentes contextos/cotidianos educacionais.

Reforçando as discussões anteriores, os autores trazem para educação física um saber fazer que extrapola métodos e técnicas, focando na autonomia e na capacidade crítica do professor para direcionar seus próprios caminhos por meio do conhecimento da realidade. É possível visualizar também nessa citação que há um estímulo a ações pedagógicas que brotem de atitudes proativas, em que os professores possam identificar quais possibilidades cada aluno tem e assim contribuir para o desenvolvimento de suas potencialidades.

Em complemento a esse posicionamento, Carmo (2013) defende que os conhecimentos conteudistas não são suficientes para o educador, é preciso promover 


\section{RevistAleph}

uma mudança que supere valores e crenças que estão enraizadas na forma de olhar e de se relacionar com o outro e com o conhecimento. Entende-se, desse modo, que possuir acesso ao conhecimento das características das deficiências é importante, mas não assegura a inclusão e aprendizagem do aluno, tendo em vista que não há ninguém igual, mesmo que tenha a mesma deficiência.

Contudo, a discussão sobre a subjetividade do corpo não é novidade para educação física, principalmente com base na fenomenologia ${ }^{10}$, que defende um corpo pleno de subjetividade e de historicidade, constituído a partir do mundo vivido. São nas experiências vividas que se percebe os objetos, as pessoas e o mundo, acrescentando sentidos históricos, sociais, culturais e afetivos, construindo assim conhecimentos. Trata-se da discussão sobre o corpo como lugar de aprendizagem a partir das experiências vividas (NÓBREGA, 2009).

Nessa linha de pensamento sobre o corpo na perspectiva fenomenológica, reporta-se a Dias (2012, p. 75) que, ao estudar o corpo a partir da pedagogia de Freinet, mostra que, se a criança fosse recebida de corpo inteiro na escola, compreenderia melhor seu papel no mundo, pois "seu corpo não seria apenas visto, mas também seria tocado, percebido e ouvido, o que garantiria que a escola seria um lugar onde o sujeito e sua existência fossem prioridades", proporcionando outra percepção de mundo, mais rica e qualitativamente mais significante para ela.

Então, acredita-se que o desejo do professor de educação física em obter principalmente conhecimentos sobre atividades práticas, que contemplem os alunos com deficiência, como se isso fosse o único caminho para o êxito nas aulas inclusivas, parece ser um equívoco. Além de desconsiderar a subjetividade dos seus alunos, reduz a compreensão sobre a educação inclusiva.

Nessa perspectiva, compreende-se que o papel da Educação Física diante da inclusão é muito mais que garantir a participação dos alunos nas aulas, passa pelo entendimento do corpo como condição de vida, de existência, de conhecimento, que

\footnotetext{
${ }^{10}$ A fenomenologia é o estudo das essências, e todos os problemas, segundo ela, resumem-se em definir essências. Compreende o corpo numa dimensão ontológica e epistemológica, como nosso meio geral de estar no mundo. O corpo é o veículo do ser no mundo vivido. MERLEAU-PONTY, Maurice. Fenomenologia da percepção. Trad. Carlos Alberto R. de Moura. 3. ed. São Paulo: Martins Fontes, 2006.
} 


\section{RevistAleph}

precisa ter acesso às diferentes possibilidades de práticas/vivências que favorecem a aprendizagem e o conhecimento de si e do outro, intensificando valores culturais, sociais e de qualidade de vida (FERREIRA; BARRETO, 2013). Passa também por uma abordagem que valoriza a diversidade de corpos presentes na escola, bem como por procedimentos pedagógicos que repudiam o modelo competitivo tradicional de selecionar os mais aptos.

Logo, diferentes vivências corporais têm sido requisitadas a fim de se constituir uma Educação Física Inclusiva. O que têm importância, nesse momento, são as mais diversas possibilidades corporais, levando-se em consideração um novo tipo de homem, mais especificamente, outra forma de subjetividade (FERREIRA; BARRETO, 2013, p. 49).

Compreende-se, então, que alguns autores da educação física (CIDADE; FREITA, 2002); (DIAS; LOPES, 2012); (CHICON; SÁ, 2012); (FERREIRA; BARRETO, 2013) já vêm discutindo o que Glat e Blanco (2009) apontaram em suas discussões sobre essa diversidade de ofertas educativas disponibilizadas a todos. Na educação física inclusiva, a diversidade de ofertas se aplica ao oportunizar diversas práticas corporais que enriqueçam as experiências dos alunos, independentemente de suas limitações.

Nesse sentido, é possível, segundo Dias e Lopes (2012), que a Educação Física possa colaborar com o esforço coletivo de transformação da escola na construção da perspectiva inclusiva. Especialmente quando se utiliza da cultura de movimento para promover a prática da inclusão de todos os alunos, "independentemente de suas habilidades, competências, dificuldades, deficiência, condição socioeconômica e cultural - em salas de aula que atendam às necessidades dos alunos" (DIAS; LOPES, 2012, p. 75). Todavia, os caminhos ainda não estão tão claros para muitos professores e trazer elementos para pensar sobre isso pode ser uma excelente oportunidade de traçar caminhos mais condizentes com as reais necessidades presentes no chão da escola.

Assim, entende-se que a educação física pensada a partir de uma perspectiva inclusiva precisa compreender a pessoa com deficiência como um corpo que tem subjetividade e que está inserido em um contexto. Mesmo tendo necessidades 


\section{RevistAleph}

educacionais especiais, em decorrência de uma deficiência, não pode ser reduzido a uma tipologia e as suas dificuldades, pois, além das limitações, há possibilidades de aprendizagem que precisam ser contempladas. O olhar sensível do professor é fundamental para esse processo.

Contudo, apenas a mudança na forma de olhar do professor não será suficiente para garantir a inclusão dos alunos nas aulas, mas poderá abrir caminhos mais acessíveis para refletir sobre a educação inclusiva em toda a sua complexidade, favorecendo uma melhor compreensão sobre as especificidades da educação física.

\section{Considerações finais}

Diante dos dados explorados na pesquisa, percebe-se que a educação inclusiva, como uma concepção de ensino que deve contemplar todos os alunos, traz para a educação física reflexões sobre a importância de compreender de forma mais aprofundada o paradigma da inclusão, tendo em vista que a educação física ainda não se modificou de maneira significativa nas escolas dos professores pesquisados para garantir uma educação que de fato seja inclusiva.

Embora trinta dos trinta e nove professores pesquisados compreendam o paradigma da inclusão como direito de todos, ainda há dificuldades em perceber no cotidiano escolar as situações de exclusão para além das pessoas com deficiência, suscitando reflexões sobre situações de exclusão relacionadas ao gênero, biotipo, cor, raça e etnia.

Observou-se, ainda, que os professores percebem as barreiras postas ao processo de inclusão, como atitudinais, arquitetônicas, comunicacionais, e pedagógicas, bem como o pouco envolvimento administrativo dos órgãos de administração municipal e estadual. No entanto, ao justificar a ineficácia em realizar a inclusão dos seus alunos, os sujeitos pesquisados atribuem apenas ao seu saber fazer.

Além de transferir a responsabilidade da inclusão exclusivamente para seus procedimentos metodológicos, desconsiderando as barreiras já citadas, reduzem a compreensão do saber fazer, ligando-o apenas ao domínio de técnicas e métodos, uma vez que revelam não realizar a inclusão por não conseguir envolver o aluno com 


\section{RevistAleph}

deficiência, expressando, assim, o desejo de aprender sobre como realizar atividades práticas com esse aluno, como se isso fosse suficiente para oportunizar aulas inclusivas.

Entende-se que conhecer métodos e técnicas que favoreçam a realização das aulas inclusivas é importante, mas não podem ser o fio condutor da prática docente, pois muitas vezes padronizam as ações, desconsideram as subjetividades. Então, conhecer as dificuldades e, sobretudo, as possibilidades dos alunos deveria ser um caminho a ser trilhado pelos professores para, a partir disso, oferecer diferentes vivências corporais que oportunizem o acesso à cultura de movimento.

Acredita-se que, para superar essas dificuldades diante da inclusão, os professores precisam sair da posição passiva e tornar-se mais proativos, embora se compreenda que há uma grande responsabilidade política por parte de estados e municípios em ofertar cursos para os professores da rede pública de ensino. Mas cabe também a cada profissional procurar conhecer seu aluno, de modo que perceba as necessidades, estude e compreenda a deficiência e todas as barreiras vinculadas a sua exclusão. A partir de então, busque superar os desafios envolvendo-o nas aulas.

Por fim, destaca-se a importância de continuar investigando como a educação inclusiva pode contribuir para a educação física inclusiva, uma vez que é imprescindível para encontrar os entraves que impossibilitam uma aproximação com as concepções inclusivas na escola. Entende-se que um desses entraves é o pouco aprofundamento dos professores sobre as temáticas que envolvem a educação inclusiva. Como resolver isso? Já foram apontados alguns caminhos, contudo, não tem-se a pretensão de oferecer todas as possíveis soluções, mas de instigar novos estudos que possam abrir muitas outras possibilidades, ampliando as reflexões a partir de dados empíricos e de experiências positivas no campo da educação física inclusiva.

\section{Referências}

BOATO, Elvio Marcos. A educação física escolar frente aos desafios da educação inclusiva. In: CHICON, José Francisco; RODRIGUES, Graciele Massoli. Educação física e os desafios da inclusão. Vitória: EDUFES, 2010. p. 104-139. 


\section{RevistAleph}

CARMO, Apolônio Abadio do. Aspectos históricos, filosóficos e sociológicos da deficiência. In: FERREIRA, Eliana Lúcia (org.). Educação física inclusiva. Juiz de Fora: NGIME/UFJF, 2013. p. 15102. v. 2.

CARVALHO, Rosita Elder. Removendo barreiras para a aprendizagem: educação inclusiva. Porto Alegre: Mediação, 2000.

CHICON, José Francisco. Compreendendo a in/exclusão no contexto da educação física escolar. In: CHICON, José Francisco; RODRIGUES, Graciele Massoli. Educação física e os desafios da inclusão. Vitória: EDUFES, 2010. p. 66-103.

CHICON, José Francisco; SÁ, Maria das Graças Carvalho Silva de. Práticas pedagógicas inclusivas: considerações sobre a constituição da subjetividade humana. In: CHICON, José Francisco; RODRIGUES, Graciele Massoli. Práticas pedagógicas e pesquisas em educação física escolar inclusiva. Vitória: EDUFES, 2012. p. 85-108.

CIDADE, Rute Eugênia; FREITAS, Patrícia Silvestre. Educação física e inclusão: considerações para a prática pedagógica na escola. Revista Integração, Brasília, ano 14, p. 26-30, 2002. Edição especial.

DIAS, Maria Aparecida. $O$ corpo na pedagogia Freinet. 1. ed. São Paulo: Editora Livraria da Física, 2012. (Coleção Contextos da Ciência).

DIAS, Maria Aparecida; LOPES, Kátia Augusta. Educação motora para deficientes. In: Gabriel Arcanjo Santos de Albuquerque. (org.). Caderno pedagógico do ensino a distância da UFAM. 1. ed. Manaus: Editora da UFAM, 2012. p. 37-90. v. 1.

FERREIRA, Eliana Lúcia; BARRETO, Michelle Aline. Práticas corporais inclusivas. In: FERREIRA, Eliana Lúcia (org.). Educação física inclusiva. Juiz de Fora: NGIME/UFJF, 2013. p. 47-57. v. 5.

FERREIRA, Flávia Martinelli; DAOLIO, Jocimar. Educação física escolar e inclusão: alguns desencontros. Revista Kinesis, Santa Maria, v. 2, ed. 32, p. 52-68, 2014.

FERREIRA, Maria Beatriz Rocha. Jogo, representações sociais, configurações, inclusão/exclusão. In: FERREIRA, Eliana Lúcia (org.). Educação física inclusiva. Juiz de Fora: NGIME/UFJF, 2013. p. 17-100. v. 3.

GLAT, Rosana; BLANCO, Leila de Macedo Pinheiro. Educação inclusiva: cultura e cotidiano escolar. 2. ed. Rio de Janeiro: 7 Letras, 2009.

JESUS, Mauro Louzada de; DEVIDE, Fabiano Pires. Educação física escolar, co-educação e gênero: mapeando representações de discentes. Revista Movimento, Porto Alegre, v. 12, n. 03, p. 123-140, 2006.

KARAGIANNIS, Anastasios; STAINBACK, Susan; STAINBACK, William. Visão geral histórica da inclusão. In: STAINBACK, Susan; STAINBACK, William. Inclusão: um guia para educadores. Tradução de Magda França. Porto Alegre: Artmed, 1999. p. 35-47. 


\section{RevistAleph}

LEOPOLDINO, L. do N. (org.). Encontros educação física, 10 e 20 ano: manual do professor de educação física: componente curricular educação física: ensino fundamental, anos iniciais. 1 ed. São Paulo: FTD, 2018.

MANTOAN, Maria Teresa Eglér. Inclusão escolar: o que é? por quê? como fazer? São Paulo: Summus Editorial, 2004.

MANTOAN, Maria Teresa Eglér. A integração de pessoas com deficiência: contribuições para uma reflexão sobre o tema. São Paulo: Memnon, 1997.

MARTINS, Lúcia de Araújo Ramos. História da educação de pessoas com deficiência: da antiguidade ao início do século XXI. Campinas: Mercado de Letras, 2015.

MARTINS, Lúcia de Araújo Ramos. Inclusão escolar: algumas notas introdutórias. In: MARTINS, Lúcia Araújo; PIRES, José; PIRES, Gláucia Nascimento da Luz; MELO, Francisco Ricardo Lins Vieira de. Inclusão: Compartilhando saberes. 2. ed. Petrópolis/RJ: Vozes, 2006. p. 17-26. (Educação Inclusiva).

NÓBREGA, Terezinha Petrúcia da. Corporeidade e educação física: do corpo-objeto o corposujeito. 3. ed. rev. Natal: EDUFRN, 2009.

NATAL. Secretaria Municipal de Educação. Livro de registros dos encontros de formação continuada em Educação Física 2014-2017. Natal: Secretaria Municipal de Educação, 2017. No prelo.

PIRES, José. A questão ética frente às diferenças: uma perspectiva da pessoa como valor. In: MARTINS, Lúcia Araújo; PIRES, José; PIRES, Gláucia Nascimento da Luz; MELO, Francisco Ricardo Lins Vieira de. Inclusão: compartilhando saberes. Petrópolis: Vozes, 2006. p. 29-53.

SILVA, Nívia Cristiane Pereira da. Questão social e questão racial no Brasil: a visão de Octávio Ianni. Revista em Pauta: Revista da Faculdade de Serviço Social da Universidade do Estado do Rio de Janeiro, Rio de Janeiro, v. 6, n. 23, p. 191-202, 2009.

SOLER, Reinaldo. Educação física inclusiva na escola: em busca de uma escola plural. Rio de Janeiro: Sprint, 2005.

SOUZA, Maurício Teodoro de. Imagens e metáfora sobre o preconceito étnico-racial na educação, educação física e esporte. In: GIMENEZ, Roberto; FREITAS, Alessandro de. Educação física inclusiva na educação básica: reflexões, propostas e ações. 1. ed. Curitiba: Editora CRV, 2015. p. 201-218.

VÍLCHEZ, Iván Carlos Curioso. Uma escola em transformação: reflexões essenciais de uma educação inclusiva para estudantes com deficiência. In: PAPIM, Angelo Antonio Puzipe; ARAUJO, Mariane Andreuzzi de; PAIXÃO, Kátia de Moura Graça; SILVA, Glacielma de Fátima da (org.). Inclusão escolar: perspectivas e práticas pedagógicas contemporâneas. Porto Alegre: Editora Fi, 2018. p. 13-30. 